\title{
Biological Conditions in Streams of Johnson County, Kansas, and Nearby Missouri, 2003 and 2004
}

\author{
By Barry C. Poulton', Teresa J. Rasmussen², and Casey J. Lee²
}

\section{Introduction}

Johnson County is one of the fastest growing and most populated counties in Kansas. Urban development affects streams by altering stream hydrology, geomorphology, water chemistry, and habitat, which then can lead to adverse effects on fish and macroinvertebrate communities. In addition, increasing sources of contaminants in urbanizing streams results in public-health concerns associated with exposure to and consumption of contaminated water.

Biological assessments, or surveys of organisms living in aquatic environments, are crucial components of waterquality programs because they provide an indication of how well water bodies support aquatic life. This fact sheet describes current biological conditions of Johnson County streams and characterizes stream biology relative to urban development.

Biological conditions were evaluated by collecting macroinvertebrate samples from 15 stream sites in Johnson County, Kansas, in 2003 and 2004 (fig. 1). Data from seven additional sites, collected as part of a separate study with similar objectives in Kansas and Missouri (Wilkison and others, 2005), were evaluated to provide a more comprehensive assessment of watersheds that cross State boundaries. Land-use and water- and streambedsediment-quality data also were used to evaluate factors that may affect macroinvertebrate communities.

Metrics are indices used to measure, or evaluate, macroinvertebrate response to various factors such as human disturbance. Multimetric scores, which integrated 10 different metrics that measure various aspects of macroinvertebrate communities, including organism diversity, composition, toler-

${ }^{1}$ U.S. Geological Survey, Columbia Environmental Research Center, Columbia Missouri.

${ }^{2}$ U.S. Geological Survey, Lawrence, Kansas. ance, and feeding characteristics, were used to evaluate and compare biological health of Johnson County streams.

This information is useful to city and county officials for defining current biological conditions, evaluating conditions relative to State biological criteria, evaluating effects of urbanization, developing effective water-quality management plans, and documenting changes in biological conditions and water quality.
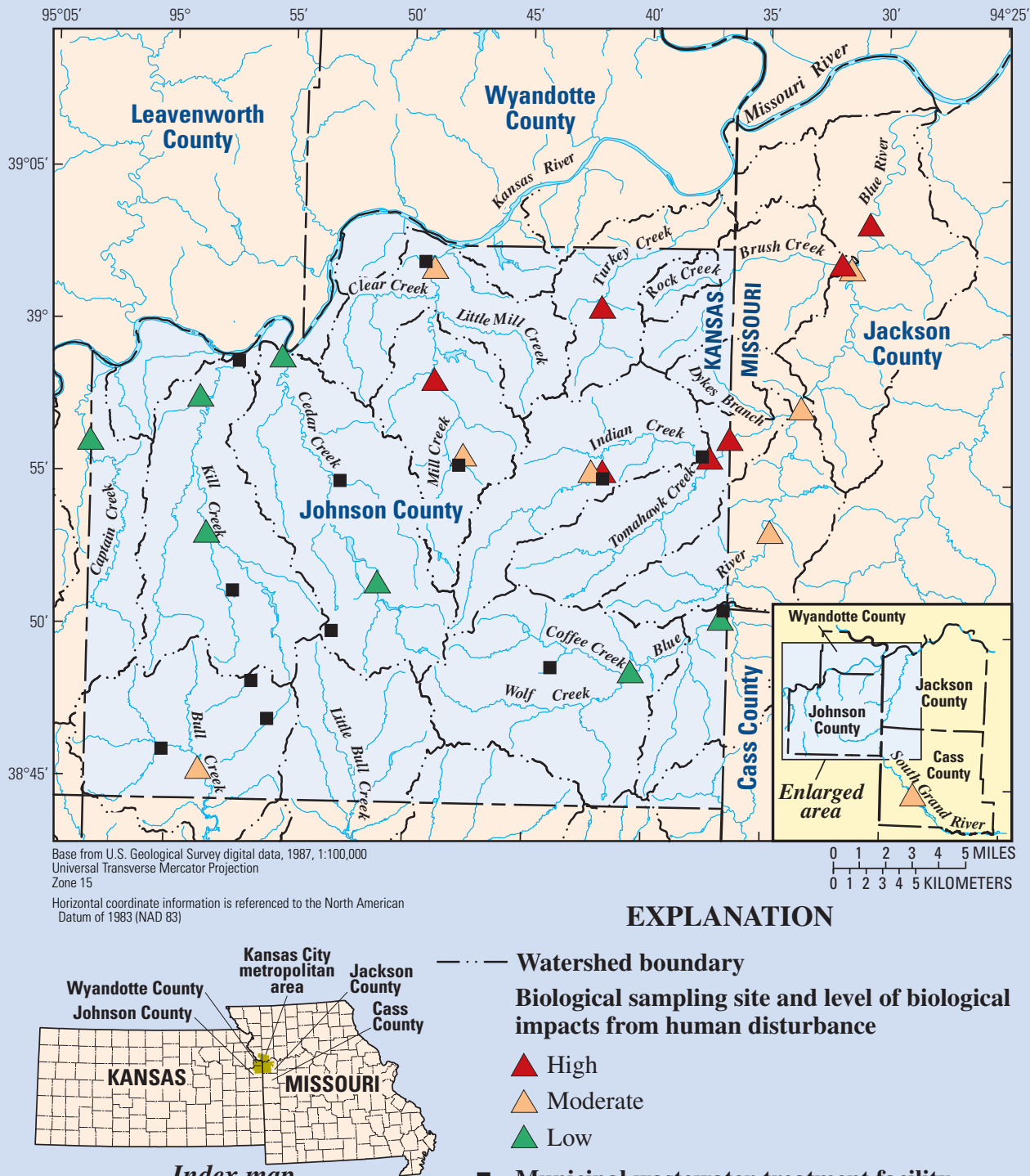

Index map

EXPLANATION

Watershed boundary

sampling site and level of biological impacts from human disturbance

$\triangle$ Moderate

- Municipal wastewater-treatment facility

Figure 1. Location of 22 macroinvertebrate sampling sites in Johnson County, Kansas, and nearby Missouri, and relative biological impacts (negative responses associated with human-induced disturbance or stress) indicated by average multimetric scores for 2003-04. 
Important Results

Biological conditions in Johnson County streams generally reflected a gradient (a continuum of observed conditions) in the cumulative effects of land-use factors upstream from sampling sites. As impervious surface area such as paved surfaces and rooftops (a general indication of increasing urbanization) increased, biological quality generally decreased.

Sites that consistently scored among those least impacted by human disturbance included upstream Blue River sites, Cedar Creek sites, and upstream Kill Creek sites, which demonstrated conditions similar to those at the reference site at Captain Creek. Reference streams are streams designated by the State as being minimally disturbed by human activity. In contrast, Johnson County sites on Indian, Tomahawk, and Turkey Creeks, and Missouri sites in downstream reaches of the Blue River and Brush Creek, ranked among the sites most impacted by human disturbance.

- No sites, including the Captain Creek reference site, met State criteria (Kansas Department of Health and Environment, 2006) for full support of aquatic life during 2003 and 2004. Stream conditions at most rural sites were partially supporting of aquatic life, and conditions at most urban sites were nonsupportive of aquatic life.

- Average macroinvertebrate scores at urban sites with wastewater-treatment facility (WWTF) discharges were slightly less than at other urban sites with no WWTF discharges. However, average macroinvertebrate scores at both of these urban groups of sites were substantially less than rural sites (indicating greater impacts from human disturbance).

The Blue River watershed, which is shared by Kansas and Missouri, has a clear upstream-to-downstream gradient in relative amount of biological impacts. The most downstream Blue River sites in Missouri, which are affected more by both urbanization and wastewater discharges, had among the lowest multimetric biological condition scores. In contrast, the two upstream Blue River sites in Johnson County had high multimetric scores and contained a diversity of organisms normally associated with good water quality.

A total of 190 different kinds of macroinvertebrates were collected during this study. Most rural sites contained a diversity of macroinvertebrates, with representation of the insect orders normally associated with healthy communities such as mayflies (Ephemeroptera), stoneflies (Plecoptera), caddisflies (Trichoptera), dragonflies and damselflies (Odonata), and riffle beetles (Coleoptera) (fig. 2). More urban sites had none or very few of these insects and were dominated by pollution-tolerant animals such as leeches (Hirudinea) and worms (Oligochaeta).

The complete report from which this information was taken (Poulton and others, 2007) is available on the Web at http://pubs.er.usgs.gov/usgspubs/

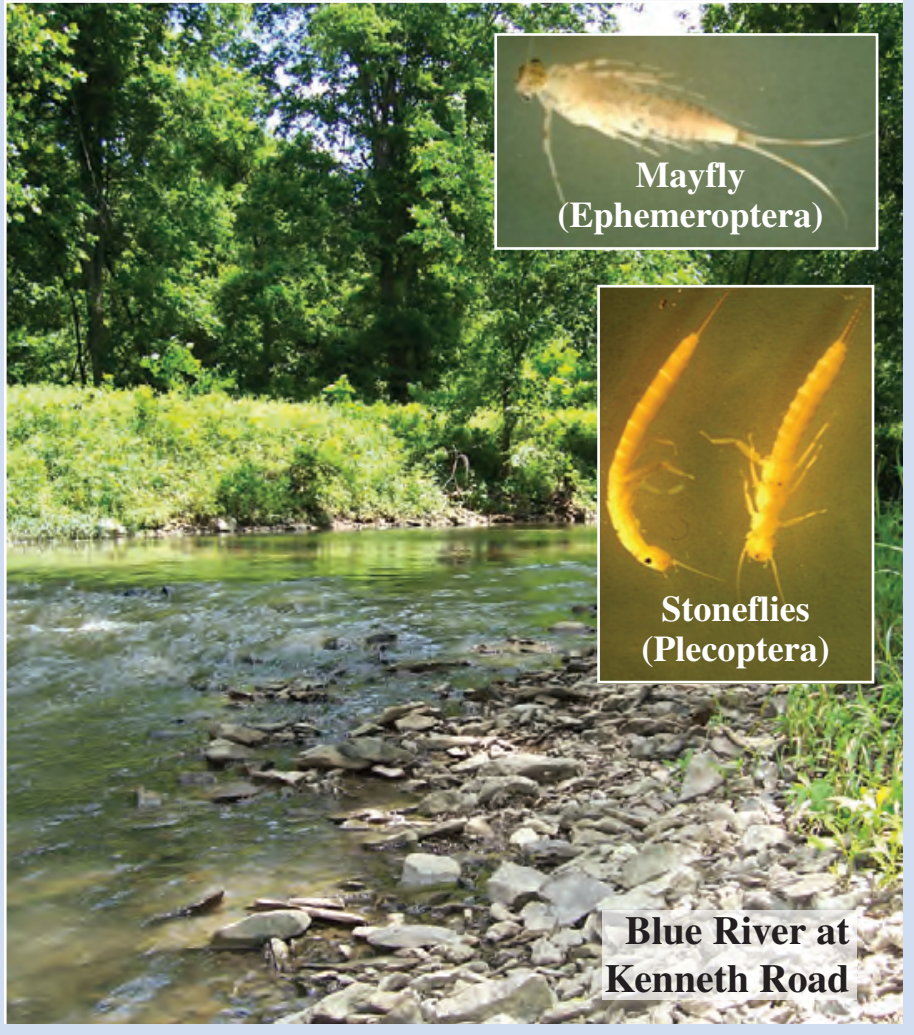

Figure 2. Example of a stream site in Johnson County, Kansas, showing minimal impacts from human disturbance and the macroinvertebrates generally associated with healthy streams (macroinvertebrate photographs from http://www.epa.gov/ bioindicators/html/photos_invertebrates.htm/.

\section{References}

Kansas Department of Health and Environment, 2006, Kansas water quality assessment, report 305b: Topeka, Kansas, 20 p.

Poulton, B.P., Rasmussen, T.J., and Lee, C.J., 2007, Assessment of biological conditions at selected stream sites in Johnson County, Kansas, and Cass and Jackson Counties, Missouri, 2003 and 2004: U.S. Geological Survey Scientific Investigations Report 2007-5108, 68 p.

Wilkison, D.H., Armstrong, D.J., Brown, R.E., Poulton, B.C., Cahill, J.D., and Zaugg, S.D., 2005, Water-quality and biologic data for the Blue River Basin, Kansas City metropolitan area, Missouri and Kansas, October 2000 to October 2004: U.S. Geological Survey Data Series 127, 158 p.

\section{For additional information visit the USGS Web site at: http://ks.water.usgs.gov/Kansas/studies/qw/joco/ \\ or contact: \\ U.S. Geological Survey \\ Director, Kansas Water Science Center \\ 4821 Quail Crest Place \\ Lawrence, Kansas 66049-3839 \\ (785) 842-9909 or E-mail: dc_ks.usgs.gov}

Prepared by the Lawrence Publishing Service Center 